\title{
Exploring Reviewer Reactions to MA Theses of Foreign Linguistics and Applied Linguistics
}

\author{
Zhencong Liu \\ Beijing International Studies University, Beijing, China \\ Tong Jia \\ Beijing International Studies University, Beijing, China \\ Tinghe Zhang \\ Beijing International Studies University, Beijing, China
}

\begin{abstract}
MA theses are the most important and the last step for them to attain their degree; however, their graduation dissertations must get the approval from the outside expert reviewers. Based on the analysis of 64 outside expert reviewers' reactions to the MA theses of students majoring in foreign linguistics and applied linguistics, this paper is designed to classify the expert reviewers' comments and find out the core factors that expert reviewers mostly pay attention to. Through the classifications and analysis of all the remarks, it can be seen that research background, language and research methodology are the frequently assessed part. At the end of the paper, the author gives some suggestions for both graduate students and tutors on how to efficiently avoid the common problems in the writing of the MA theses.
\end{abstract}

Index Terms - expert reviewers' reactions, MA theses, problems of graduation dissertations

\section{INTRODUCTION}

Because of the popularity and importance of English, more and more universities are allowed to train masters who major in English; also more and more students try their best to pursue their master degrees to gain a better life. With the reform of higher education, the government and society put more emphasis on masters' qualities, so the students who are in pursuit of their master degree face more and more challenges. It is reported that every year, more than 30 universities expand their training scale of graduates (Yan, Yang \& Yu, 2014). Under this circumstance, more and more educators have been aware of the quality of postgraduates (Huo, 2013).

As the reflection of research ability, MA theses represent masters' comprehensive ability, not only their research ability, but also their writing competence. The theses of graduate students are the certificate for them to pursue their degree, so the quality of their papers must be guaranteed. In order to examine the quality of graduate students' thesis papers, expert reviewer evaluation is an indispensable part.

After graduate students finish their drafts of thesis papers, they submit their papers to their tutors and their tutors will evaluate the papers. This process will last for several times until the tutor thinks the paper has met the requirements of the MA theses. Then the graduate students submit the final draft of their thesis papers to school, the school will submit all of these thesis papers anonymously to outside expert reviewers from other different universities for further evaluation. In the review process, every MA theses will be submitted to three expert reviewers. The thesis paper should receive the affirmation from three expert reviewers, and then the student can graduate. However, if one expert reviewer fails the paper, then the paper will be submitted to another two expert reviewers, and this time the paper must receive both expert reviewers' affirmation; otherwise, the student is unable to graduate on time.

The evaluation of the thesis papers usually has a set of standards: topic, significance of the thesis paper, research ability as well as the normalization. Every aspect of evaluation has its own emphasis. As for the topic, the evaluation lies in that whether the topic is up to date, the significance of the topic, and whether the paper depicts a thorough picture of the field related to this topic. In terms of implication of the thesis paper, the assessment focuses on the paper's contribution to the future research or knowledge. When it comes to the research ability, the evaluation mainly examines the appropriacy of methodology of the paper, the citation of the paper and the student's knowledge level, while the normalization of the thesis paper is aimed to assess the structure, language quality, fluency of the thesis paper.

Based on the analysis of 64 expert reviewers' reactions to the MA theses, the current paper aims to classify the reactions and find out the common problems of MA theses. In light of the research findings, the end of the paper will give some useful suggestions for both graduate students and tutors.

\section{LITERATURE REVIEW}

Up to now, there have been a lot of studies related to outside peer review, which can be summarized as follows. 
Firstly, research has been done in the field of the application of peer review in different subjects. Larson and Chung (2012) investigated the peer review for scientific manuscripts and found out the usefulness of peer review. However, there was a lack of systematic reviews to date to highlight the essential themes of the peer review process. Coniam (2012) focused on the reviewer reactions to manuscripts submitted to academic journals, in which the author classified the reviewer reactions into different categories and described a rather detailed review process. In addition, as for different fields, what standards were used to evaluate the papers by the peer reviewers was another hot issue. Molly, Margaret C., Margaret H., Judith and Marion (2010) conducted an online survey of nursing peer reviews. In order to assure the graduate degree thesis papers quality, in addition to internal management, outside peer review, as external monitoring, was also an indispensable part (Yao et al., 2011).

Secondly, research has been done in the field of backwash effect of peer review system. Taking the masters' graduation thesis papers of students majoring in medical science for example, Liu and Xing (2016) analyzed the peer review outcomes. Then, they proposed that as for the application of peer review, there was still room for improvement. From the feedback of outside peer review, it could be found that students should focus on their dissertation writing, from topic selection, design to writing and modification. In addition to students themselves, their supervisors also played rather important roles in the dissertations. If the supervisors were responsible and knowledgeable, they could provide timely and valuable help for their students during the process of thesis papers writing (Huang et al., 2008). Yu, He and Zhang (2013) adopted analytic hierarchy process to analyze the outcomes of doctors' dissertations, trying to compare the cultivation quality of doctors. Through comparing two years' feedback of peer review, Luo, Sun and Wu (2008) found that more and more students could select meaningful and worthwhile topics, design more reasonable experiment and compile higher quality thesis papers. However, some students still did worse in writing thesis papers, for they perhaps read enough journals, but they lacked opportunities to writing English journals, which was an important point for future academic writing teaching.

Thirdly, research has been done in the field of the peer review's reliability and changes before and after peer review. Kyle and Strang (2016) examined the criticisms and subsequent changes that arose in the course of peer review and investigated 52 authors regarding their peer review experience and how their article changed from initial journal submission to final publication. A system for random sampling and anonymous peer review for graduate dissertations was invented. With the application of the system, the work of dissertation review was completed successfully and in return improved the quality of graduate students' cultivation (Meng, 2015).

Fourthly, research has been done in the field of the policy of using peer review to evaluate students' graduation dissertations. Jia and Yun (2008) firstly affirmed the usefulness of outside peer review system, because it was a vital part in evaluating the masters' MA theses. However, there were also some problems of present system, such as: narrow selection of outside peer reviewers, unsuitable major, non-unified appraisal standard and so on. Therefore, it was highly necessary to strengthen the concept, attach importance to expert training and put up effective system of supervision. What's more, although peer review system is an inevitable trend, different universities have their own specific requirements. Zhang (2012) analyzed the peer review system of Yulin University. On one hand, peer review system has its own strengths; for example, it can stimulate both the students and their supervisors to pay more attention to the thesis papers, which can improve the teaching quality in return. However, on the other hand, the whole process of peer review should be supervised strictly, from the policy of peer review announced to the peer review system applied. Indeed, outside peer review was an essential step for students to ask for their degree; however, current outside peer review system had its own weaknesses. Liu (2011) indicated that the research direction of the outside expert may not be in line with that of the graduate thesis paper, so the feedback may not be that convincing. Furthermore, faced with the same evaluation criteria, different experts may hold different ideas, and this situation was more common in the evaluation of interdisciplinary thesis papers.

\section{METHOD}

\section{A. Participants}

The participants are postgraduate students who have been graduated in 2016. They all come from the department of English Education in Beijing International Studies University. They were majored in foreign linguistics and applied linguistics. They were from three different programs, namely English education, business English and cross-culture communication. In addition to students, there are 64 off-campus reviewers. They are all the experts in the corresponding domains, such as the experts in English education who come from Beijing Normal University, the experts in international business English who come from University of International Business and Economics and so on. Most of them are professors and as the tutors of the doctoral students. They are experienced reviewers.

\section{B. Data Collection}

Altogether 64 reviewer reactions to MA theses of foreign linguistics and applied linguistics were collected for the sake of investigating how these evaluations of expert reviewers were distributed. The author collected the reviewer reaction with the help of colleagues and other teachers. All the reviewer reactions follow the same pattern, listing the evaluations in terms of topic selection, significance of the topic, research ability and normalization of the thesis paper. In addition to those general ratings and an overall mark of the thesis paper, the expert reviewer also pointed out the 
advantages and disadvantages of every dissertation. All of these reviewer reactions were labeled with numbers.

\section{Data Analysis}

Coniam (2012) once explored reviewer reactions to manuscripts submitted to academic journals, and designed a theoretical scheme with 19 specific categories. All these categories can be divided into four general headings, namely scholarly background, originality and relevance, research methodology as well as language. After exploring the outside experts' feedback of masters' MA theses, taking the distinct situation of the masters' MA theses into consideration, the authors modified and revised the original scheme to retain a new scheme according to the outside experts' rating scale. The current scheme was made up of four parts, and each part consisted of several sub-parts, which reflected the overall quality of the thesis paper (see Table 1).

TABLE 1

ANALYTIC DIMENSIONS

\begin{tabular}{|l|l|}
\hline \multirow{4}{*}{ Research Background } & Theoretical background \\
\cline { 2 - 2 } & Research significance \\
\cline { 2 - 2 } & Creativity of the paper \\
\cline { 2 - 2 } $\begin{array}{l}\text { Academic Ability and } \\
\text { Appropriacy }\end{array}$ & Potential implication \\
\hline \multirow{3}{*}{ Language } & Normalization of literature review \\
\cline { 2 - 2 } & Normalization of quotation \\
\hline \multirow{2}{*}{ Research Methodology } & Structure of the paper \\
\cline { 2 - 2 } & Quality of the language \\
\cline { 2 - 2 } & Logic of the paper \\
\hline
\end{tabular}

The collected expert reviewer reactions are classified under the help of computer. 64 outside expert reviewer reactions are firstly labeled by ticks. And the each piece of evaluation is expressed with a tick or no tick. A tick " $\sqrt{ }$ " represents that the evaluation is shown in the expert reviewer's reactions, while no tick means that the evaluation is not included in the expert reviewer's reactions. However, sometimes the expert reviewer's reactions are ambiguous, mentioning the evaluation of two facets, so under this circumstance, this piece of evaluation is classified into the both sub-parts.

\section{FINDINGS AND DisCUSSION}

Through the analysis of 64 reviewers' reactions, the author classifies the expert reviewers' reactions into four aspects in general: research background, academic ability and appropriacy, language and research methodology. Furthermore, every general aspect can be divided into specific sub parts. In terms of research background, it can be further divided into theoretical background, research significance, creativity of the paper and potential implication. As for academic ability and appropriacy, it can be divided into normalization of literature review as well as normalization of quotation. When it comes to language, it includes structure of the paper, quality of the language together with logic of the paper, while research methodology part contains research methodology and adequacy of the research question. The specific analytic categories can be seen in Table 2 .

TABLE 2

SPECIFIC DISTRIBUTION OF REVIEWERS'REACTIONS

\begin{tabular}{|l|l|l|l|}
\hline \multirow{4}{*}{ Research Background } & Evaluation Item & Number & Percentage \\
\cline { 2 - 3 } & Theoretical background & 59 & $92.19 \%$ \\
\cline { 2 - 3 } & Research significance & 56 & $87.5 \%$ \\
\cline { 2 - 3 } & Creativity of the paper & 29 & $45.31 \%$ \\
\cline { 2 - 3 } & Potential implication & 31 & $48.44 \%$ \\
\hline \multirow{3}{*}{$\begin{array}{l}\text { Academic Ability and } \\
\text { Appropriacy }\end{array}$} & Normalization of literature review & 13 & $20.31 \%$ \\
\cline { 2 - 4 } Language & Normalization of quotation & 25 & $39.06 \%$ \\
\hline \multirow{3}{*}{ Research Methodology } & Structure of the paper & 44 & $68.75 \%$ \\
\cline { 2 - 4 } & Quality of the language & 51 & $79.69 \%$ \\
\cline { 2 - 4 } & Logic of the paper & 31 & $48.44 \%$ \\
\cline { 2 - 4 } & Research methodology & 45 & $70.31 \%$ \\
\cline { 2 - 4 } & Adequacy of the research question & 14 & $21.88 \%$ \\
\hline
\end{tabular}

\section{A. Research Background}

Research background part includes four sub parts, theoretical background, research significance, creativity of the dissertation and potential implication. Research background is the basis of the topic selection, because when graduate students have mastered enough and comprehensive knowledge of certain field, he/she can have a better understanding of this field and select a topic worth exploring. Moreover, the topic selection also affects its significance and implication.

Firstly, altogether 59 out of 64 outside expert reviewer reactions mention comments concerning theoretical 
background, which implies the theoretical background is of vital importance in masters' thesis papers. Most of the experts firstly introduce the background of the study based on the graduate students' dissertations, and then give comments on the thesis papers in terms of the area graduate students choose, which is a common pattern in expert reviewers' reactions. For example:

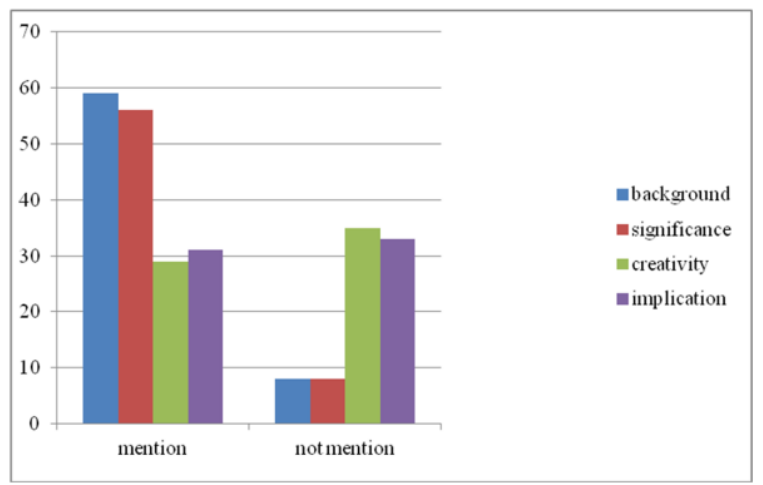

Figure 1 Distributions of Comments on Research Background, Significance, Creativity and Implication (made by the second author)

Example1: This paper explores the current situation of postgraduate geoscience majors' English academic paper writing based on need analysis and has a rational discussion (translated from Chinese, Expert 1 in paper ID: 100312013110169).

Example 2: The study entitled the study on Sino-US differences of social responsibilities of companies in terms of cross-cultural angle, aims to analyze the situation of China Oil and Foodstuffs Corporation emerging into the world, which has good practical meaning (translated from Chinese, Expert 2 in paper ID: 100312013110178).

Example 3: The paper conducts an empirical study on vocabulary teaching of Business English based on Chunk Theory, which contains rich theoretical significance (translated from Chinese, Expert 3 in paper ID: 100312016000006).

From the above three examples, it can be found that the expert reviewers firstly review the background of the research, and give an overall comment of the research basis. Research background lays a solid foundation of the study, so the research background is indeed of vital importance for a paper. Only after clarifying the research background, can the graduates find the appropriate starting point of their papers. However, in addition to the outside experts' positive reactions, there is also some negative feedback from the outside experts.

Example 4: Based on testing theory, this dissertation tries to compare the differences of reading test of Test for English Majors Band 4 (TEM-4) and College English Test Band 6 (CET-6) in content validity and washback effect. Furthermore, the author chooses two different kinds of tests, which are used to test different levels of students, so there are not some points worth of comparing. However, actually, the paper does not involve any useful washback effect (translated from Chinese, Expert 4 in paper ID: 100312013110168).

The pattern still accords with the traditional structure, from the general review of the topic to the outside expert's comments. But this feedback is a negative one, which indicates that the chosen topic and research angle need to be revised. Although when the graduates select their research field and topic, they nearly master some related theories and have their own ideas, they still need their supervisors to lead them to explore whether the topic is worth doing. Indeed, for the supervisors, this throws light upon the cultivation of masters. The supervisors can pay much attention to the research background of their students' thesis papers to ensure the students make an explicit statement of the research background. As for the students, they should accumulate enough theories to prepare for their dissertation writing.

Secondly, in general, 56 out of 64 expert reviewer reactions mention comments about research significance, which can be seen that research significance also is an essential part in determining the quality of graduate students' thesis papers. Expert reviewers usually decide the dissertation's significance from both theoretical usefulness and practical value.

Example 5: The paper presents great theoretical and practical significance (translated from Chinese, Expert 5 in paper ID: 100312013110171).

Example 6: Actually, the paper provides guidance for the current English teaching and education, and is also helpful for students' autonomic learning (translated from Chinese, Expert 6 in paper ID: 100312013110176).

Example 7: This paper has good practical significance and theoretical meaning to some extent (translated from Chinese, Expert 7 in paper ID: 100312013110183).

Example 8: The selection of the topic has valuable practical meaning, which shades light on the future's English teaching (translated from Chinese, Expert 8 in paper ID: 100312016000011).

The above examples present that most expert reviewers just give a rather general comment in terms of the significance of the research. The significance, either theoretical significance or practical significance depends on the selection of the topic, so the selection of the topic is the foundation. When choosing the research field or topic, both the students and the supervisors should take the significance of the research into consideration, which provides the direction 
for future academic writing teaching.

Thirdly, in general, nearly half of the expert reviewer reactions mention comments contain creativity of the paper part. In one outside expert's reaction, the expert says that: "The current study uses those existed theories to analyze the selected corpus, failing to put forward any new idea", which directly points out the dissertation lacking creativity. In addition, "Creativity needs to be improved" is another common evaluation in the expert reviewers' reactions from which it can be seen that currently graduate students lack creativity, that is to say, they cannot transfer what they have learned theoretically to practice. While on the other hand, some graduate students choose a rather worthy topic, combining the theory and practice, and once solved properly, it will expand the theory or provide the cases for the theory.

Example 9: The paper has a good pointcut and it is very creative (translated from Chinese, Expert 9 in paper ID: 100312013110170).

Example 10: The paper imitates the previous studies, so it does not have creativity (translated from Chinese, Expert 10 in paper ID: 100312016000015 ).

We can see from the above examples that the expert reviewers judge whether the paper is creative from the selection of the topic and the background of the research. Therefore, it is of great essence for students to make a detailed review of the research background. Based on the research background, the research questions can be proposed appropriately. And the study should be closely associated with the theory itself or the application of the theory. Creativity is an ability that every graduate should develop. As for this facet, in order to assist the students, the supervisors can introduce the latest journals to students, which can help know the developing trend of the field. As for students themselves, they should develop their critical mind; when they read some journals, they should transfer what they read to thought and based on the articles, they should put forward their own ideas and comments, trying to find the research gap, which is their creative point.

Fourthly, all in all, 31 expert reviewer reactions include comments about potential implication, especially common in thesis papers of students majoring English education, because the application of a certain teaching theory may easily give implication for future language teaching and learning. However, some expert reviewers use ambiguous comment, which is difficult to judge whether the comment falls into the significance of the paper or the potential implication, so in this case, the authors divide this kind of evaluation into the both two dimensions. As dimension of potential implication is a necessary part in expert review feedback, graduate should take the implication of paper into consideration when choosing the topic. Potential implication indicates the usefulness of the study. If the study has enough potential implications, then the subsequent scholars can learn from the current study and then find their own starting point. For instance:

Example 11: The conclusion of the study is reliable, and it has some implications on future teaching (translated from Chinese, Expert 11 in paper ID: 100312013110184).

Example 12: The results of the study have been testified, which is worth being popularized (translated from Chinese, Expert 12 in paper ID: 100312016000009$)$.

For this sub-part, the expert reviewers also just give a general comment in simple words. If the research design is reasonable, and then the results of the study can be reliable, so the results can offer some implications both from the theoretical perspective and practical perspective.

\section{B. Academic Ability and Appropriacy}

As for academic ability and appropriacy, expert reviewers evaluate the dissertations from the normalization of literature review and the normalization of citation. No matter literature review or the citation of others' studies can embody the graduate students' research competence. On one hand, writing ability is one of the most important ability to reflect graduate students overall English proficiency, while on the hand, whether graduates can write the literature review appropriately can reflect their understanding of previous studies of the similar topic home and abroad. However, only one third of the remarks involve the comments of academic ability and appropriacy, which means expert reviewers evaluate the paper from a rather general perspective and seldom focus on such specific part. Common remarks are that the citation follows a good pattern, or the format of the citation needs to be improved and revised.

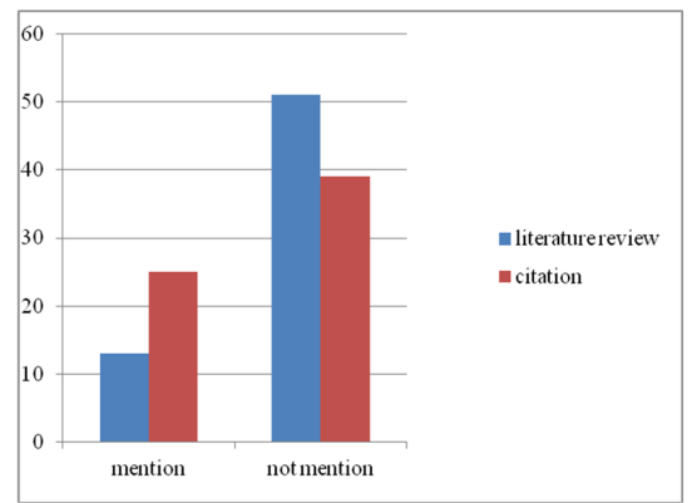

Figure 2 Distributions of Comments on Normalization of Literature Review and Citation (made by the second author) 
Example 13: The paper gives a well-rounded description of the related theories and practices in literature review, representing the author's good research ability (translated from Chinese, Expert 9 in paper ID: 100312013110170).

Example 14: The paper should reorganize the related studies, and follow an appropriate pattern to cite previous studies (translated from Chinese, Expert 13 in paper ID: 100312013110180).

Example 15: The results of the previous studies do not need to list in the literature review; on the contrary, literature review should summarize the related studies (translated from Chinese, Expert 2 in paper ID: 100312013110178).

The above examples show that nearly one fifth comments concerning the writing of literature review, and nearly one third comments about the normalization of the citation of others' studies. Literature part is another essential part in the graduates' thesis papers, because the writing of literature review can reflect the students' comprehensive understanding and mastery of the previous related studies. Only after students absorb other previous studies related to his or her research, can he or she find the research gap and better design the research procedure. Therefore, the writing of literature review should be put emphasis. On one hand, for instructors in the university, they should train students to read more journals, and then teach students how to write literature review. While on the other hand, as for students themselves, they should browse through more journals or articles, and develop their critical thinking, so that they can absorb the previous studies better.

\section{Language}

Through the analysis of expert reviewers' reactions, comments related to language usually fall into the following three aspects: structure of the paper, quality of the language as well as logic of the paper. Language is a core part, which receives many comments, because language is not only a basic representation of graduate students' English competence, but also a tool for graduate students to convey his/her own opinion to the readers. Expert reviewers usually mention that the language is natural and fluent, which can fully demonstrate the main idea of the paper; however, on the contrary, the expert reviewer may contend that, the words and expressions are chaotic with many mistakes in the dissertation.

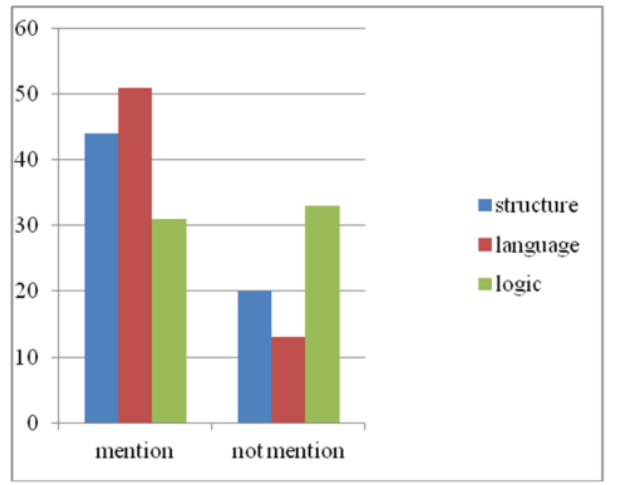

Figure 3 Distributions of Comments on the Structure, Language and Logic (made by the second author)

Example 16: The structure of the paper is reasonable (translated from Chinese, Expert 14 in paper ID: 100312013110173).

Example 17: The arrangement of some chapters needs to be improved, for it is chaotic (translated from Chinese, Expert 15 in paper ID: 100312013110176).

Example 18: The language is fluent, and quality of the language meets the requirements of the degree of master (translated from Chinese, Expert 16 in paper ID: 100312013110174).

Example 19: There are many mistakes in the paper, so the paper needs a thorough revision (translated from Chinese, Expert 17 in paper ID: 100312016000014 ).

Example 20: The choice of the vocabulary should be checked again (translated from Chinese, Expert 4 in paper ID: 100312013110168).

Example 21: The logic of the paper is rather clear, making it easy for the readers to understand (translated from Chinese, Expert 18 in paper ID: 100312016000012).

The above examples, including both positive comments and negative feedback, expound that language is also an essential part that attracts many expert reviewers' attention. Language, involving not only the use of vocabulary and grammar, but also the structure and the logic of the paper, is the comprehensive reflection of the students' English proficiency, and everything should be expressed in the form of language. Therefore, graduates should try their best to polish their language proficiency. In addition, students should pay attention to the academic language, for some graduates tend to use some colloquial or informal expressions in the papers, which is inappropriate.

As for instructors, they should avoid the idea that for masters, language is not a problem any longer. There is not the same equivalent in another language, so sometimes it is difficult to express one idea in another language. Especially for academic paper writing, it is different from composition or essay writing. Chinglish expressions even appear in some masters' MA theses. Therefore, the supervisors or the instructors can provide students with more opportunities to write their academic papers, which puts them a step closer to their dissertation. Instructors can also summarize some common 
academic lists of words and expressions in class for the graduates.

\section{Research Methodology}

Research methodology is so important in thesis paper writing that it decides whether the research question can be solved. As a consequence, nearly all of the reactions contain comments on research methodology. Currently, mainly most of the thesis papers adopt research methods of both qualitative and quantitative study, which can yield more convincing results. And it is advocated that graduate students design the experiment according to the research questions and also introduce some new technologies or methods to conduct the study, which shows the creativity of the research, and it is also the indirect reflection of one's research ability.

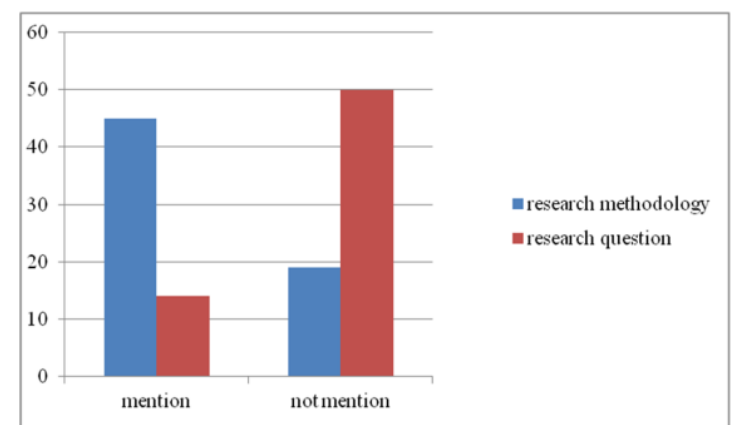

Figure 3 Distributions of Comments on the Research Methodology and the Adequacy of Research Question (made by the second author)

Example 22: The paper combines quantitative method and qualitative method, reaching a rather reasonable conclusion (translated from Chinese, Expert 1 in paper ID: 100312013110169).

Example 23: The paper analyzes the data scientifically, so the results are convincing (translated from Chinese, Expert 19 in paper ID: 10031201311080 ).

Example 24: The design of the questionnaire needs to be questioned (translated from Chinese, Expert 20 in paper ID: 100312016000010).

Example 25: The research questions are too general to solve (translated from Chinese, Expert 21 in paper ID: 100312013110182).

Example 26: The description of the research questions is not detailed and scientific enough (translated from Chinese, Expert 22 in paper ID: 100312016000017).

Research questions are the core of the study, for they lead the direction of the research. Furthermore, nearly two thirds of the comments focus on the research methodology, for research methodology is the basis of solving the pre-designed research questions. And the above examples are typical ones from all the comments. It can be seen that if the research questions are too broad, then the whole study will lose its direction; while if the research questions are too narrow, then the study will be not deep. Only after the research questions are put forward appropriately, is the tone of the research decided. In order to solve the research questions, research methodology must be selected accordingly, for every kind of research method has its own strengths and weaknesses. Therefore, for students, they should pay more attention to the research questions and the selection of the methodology, for the paper is based on the research questions and through the research methods, the research questions can be solved. While for the instructors, they should introduce more kinds of methods to students, and encourage students to apply advanced and multi-methods to their research.

\section{CONCLUSion}

MA these are the condensed embodiment of graduate students' academic ability, because graduation dissertations do not only embody students' writing proficiency, but also represent graduates' academic competence. Furthermore, as graduation dissertation is the certificate of graduate students to pursue their degree, the quality of MA theses should be given the top priority. Meanwhile, as the necessary part of evaluating the graduation dissertations, outside peer review can reveal many problems in the writing of the graduation dissertations. Therefore, no matter graduate students or tutors should check the items in the expert reviewer reactions to assure that the completion of the graduation dissertations have met the requirements of masters' degree.

As for students, they should accumulate more during their graduate study, so they can choose the creative and appropriate topic, propose the feasible research question, design the procedure reasonably and reach a convincing conclusion. Meanwhile, as instructor, they should lead students to explore the academic world, introduce more methods to the students, monitor the process of the students' dissertation writing, and communicate with the students more frequently to find out their difficulties.

\section{REFERENCES}

[1] Coniam, D. (2012). Exploring reviewer reactions to manuscripts submitted to academic journals. System 40: 544-553. 
[2] Huang, B., Li, W., Lan, T.,\& Xie, Z. (2008). Reflection and measures of cultivation quality of doctoral candidates---based on the analysis and research of doctoral dissertations' results of experts review. Journal of Inner Mongolia Agricultural University (Social Science Edition) 10(4):171-172. (In Chinese, my translation)

[3] Huo, D. (2013). Research on quality assurance system of graduate education in China under the perspective of international comparison. Master thesis paper. Nanjing: Nanjing University of Aeronautics and Astronautics.

[4] Jia, Y. \& Yun, S. (2008). Thought to Outside Peer Review System of Master Degree Thesis of P. E. in Hebei. Journal of Hebei Institute of Physical Education 22(3):28-30.

[5] Kyle, S., \& Strang, D. (2016). Peer review and scholarly originality. Research Article 42(1): 29-61.

[6] Larson, B. P., \& Chung, K. C. (2012). A systematic review of peer review for scientific manuscripts. Review Article 7(1): $37-44$.

[7] Liu, J. \& Xing, J. (2016). Analysis and improvement measures based on the results of expert review of medicine major students' MA theses. Journal of Hebei United University (Health Sciences). 18(1): 74-75. (In Chinese, my translation)

[8] Liu, L. (2011). Reflection and practice of master thesis paper's peer review system. Success (Education). (10):201-201. (In Chinese, my translation)

[9] Luo, Q., Sun, Y. \& Wu, X. (2008). Analysis of master thesis papers' peer review quality. Northwest Medical Education 16(6): 1110-1111. (In Chinese, my translation)

[10] Meng, J. (2015). Optimization of Random Sampling and Anonymous Peer Review for Shanghai Graduate Dissertations Based on the Theory of Learning Outcomes Evaluation. Shanghai Journal of Educational Evaluation (6):56-60.

[11] Molly, C. D., Margaret, C. F., Margaret, H. K., Judith, G. B., \& Marion, B. (2010). Online survey of nursing journal peer reviewers: indicators of quality in manuscripts. Review Article 33(4): 506-521.

[12] Yan, Jiang., Yang, Z. \& Yu, C. (2014). Problems and advice on system of masters' mid-term examination. Education Teaching Forum (43): 216-218. (In Chinese, my translation)

[13] Yao, Z., Zou, K., Luo, B., Kong, X. \& Zhang, L. (2011). Practice of internal management and external supervision of quality of master thesis paper---taking peer review results of thesis paper in Southeast University and that in Jiangsu Province for example. Journal of Graduate Education (5): 31-37. (In Chinese, my translation)

[14] Yu, X., He, W. \& Zhang, L. (2013). Evaluation of geosciences major doctoral dissertations' quality based on AHP method. Journal of China University of Geosciences (Social Sciences Edition) (S1): 79-82. (In Chinese, my translation)

[15] Zhang, J. (2012). Advantages, disadvantages and measures of outside expert peer review system of graduation thesis paper---taking Shaanxi Yulin University for example. Journal of Mudanjiang University 21(5): 147-149. (In Chinese, my translation)

Zhencong Liu was born in Guang Xi, China in 1969. He received his PH.D degree in Applied Linguistics from Beijing Foreign Studies University, China.

$\mathrm{He}$ is currently a vice professor in the School of Foreign Languages, Beijing International Studies University, Beijing, China. His research interests include academic writing, cognitive linguistics and English teaching.

Tong Jia was born in Da Lian, China. She received her MA degree in Applied Linguistics from Beijing Foreign Studies University, China in 2018.

She is currently a teacher in New Oriental Education \& Technology Group. Her research interest includes English teaching and writing.

Tinghe Zhang was born in Cang Zhou, China. She is currently an MA candidate in Beijing International Studies University, China. 